\title{
PERANCANGAN VIRTUAL TOUR KAMPUS I UKSW SEBAGAI MEDIA INFORMASI MAHASISWA BARU
}

\author{
Rizal Bastian Nur Budi ${ }^{1}$, Michael Bezaleel Wenas ${ }^{2}$ \\ ${ }^{1,2}$ Fakultas Teknologi Informasi, Universitas Kristen Satya Wacana \\ 692012012@student.uksw.edu ${ }^{1}$, michael.bezaleel@staff.uksw.edu²
}

\begin{abstract}
Abstrak
Kampus I Universitas Kristen Satya Wacana (UKSW) beralamat di Jalan Diponegoro 52-56 Kota Salatiga, Jawa Tengah. Memiliki luas keseluruhan $93.580 \mathrm{~m}^{2}$ terdiri dari gedung kantor dan gedung perkuliahan. Media informasi sangat penting bagi mahasiswa untuk mengenali lokasi gedung dan wilayah kampus. Berdasarkan penelitian banyak mahasiswa kesulitan menemukan lokasi gedung perkuliahan dan mengenali wilayah kampus pada awal masa perkuliahan. Media informasi yang telah ada berupa peta dua dimensi wilayah kampus hanya menyajikan informasi yang terbatas. Berdasarkan fakta tersebut, pada penelitian ini dirancang virtual tour panorama $360^{\circ}$ sebagai media informasi Kampus I UKSW untuk mempermudah mahasiswa baru dalam mengenali wilayah serta memberikan informasi awal tentang letak gedung secara visual. Metode perancangan yang digunakan adalah mixed method dan strategi linier. Hasil yang dicapai dari penelitian ini berupa virtual tour sebagai media informasi Kampus I UKSW sudah sesuai dengan harapan, dan layak diaplikasikan pada website Universitas.
\end{abstract}

Kata Kunci : UKSW, media informasi, virtual tour, panorama $360^{\circ}$, mahasiswa baru

\begin{abstract}
Campus I of Satya Wacana Christian University (SWCU) is located at Diponegoro Street 52-56 Salatiga, Central Java. Campus I UKSW has an overall area of 93,580 $\mathrm{m}^{2}$, consisting of office buildings and lecture buildings. Media information is very important for students to recognize the location of buildings and campus areas. Based on the research, many students have difficulty finding the location of the lecture building and recognize the campus area at the beginning of the lecture. The existing media information that is the two-dimensional map of the campus area presents only limited information. Based on these facts, this research designed virtual panoramic $360^{\circ}$ tour as a medium of information for Campus I SWCU to facilitate new students in recognizing the area and providing initial information about the location of the building visually. The design method used is mixed method and linear strategy. The result of this research is virtual tour as the information media of Campus I SWCU is suitable with the expectation, and it is worthy to be applied to the University website.
\end{abstract}

Keywords: SWCU, media information, virtual tour, panorama $360^{\circ}$, new students 


\section{PENDAHULUAN}

Media informasi adalah sarana komunikasi yang bisa dipergunakan untuk menyalurkan pesan dari pengirim pesan kepada penerima pesan, agar dapat merangsang pikiran, perasaan, perhatian sedemikian rupa, sehingga proses penyampaian pesan berlangsung dengan efektif dan efisien sesuai yang diharapkan (Sadiman, 2002). Media informasi dapat disimpulkan sebagai alat untuk mengumpulkan serta menyusun kembali sebuah informasi sehingga menjadi bahan yang bermanfaat bagi penerima informasi. Adapun penjelasan Sobur, media informasi merupakan alat-alat grafis, fotografis atau elektronis untuk menangkap, memproses, serta menyusun kembali informasi visual. Jenis-jenis media Informasi sebagai alat yang dapat menyampaikan suatu informasi harus tepat sasaran agar dapat tersampaikan dengan baik pada target sasaran sehingga bisa bermanfaat bagi pembuat maupun penerima informasi (Sobur, 2006).

Universitas Kristen Satya Wacana (UKSW) merupakan Universitas yang terletak di Kota Salatiga, Jawa Tengah. Kampus I UKSW beralamat di Jalan Diponegoro 52-56 Kota Salatiga, Jawa Tengah. UKSW semula lahir dengan nama Perguruan Tinggi Pendidikan Guru Kristen Indonesia (PTPG-KI). Diresmikan pada tanggal 30 November 1956 dengan lima jurusan, yaitu Pendidikan, Sejarah, Bahasa Inggris, Hukum, dan Ekonomi. PTPG-KI Satya Wacana berubah menjadi FKIP-KI pada tanggal 17 Juli 1959. Kemudian pada tanggal 5 Desember 1959 diresmikan menjadi Universitas Kristen Satya Wacana dengan kehadiran Fakultas Ekonomi dan Fakultas Hukum yang kemudian diikuti dengan pembukaan beberapa Fakultas dan Program Studi baru. Pada saat ini UKSW memiliki 51 Program Studi yang terdiri dari 7 Program Studi Diploma 3, 31 Program Studi Program Sarjana (S1), 10 Program Studi Program Magister (S2), dan 3 Program Studi Program Doktoral (S3) (Orientasi Mahasiswa Baru UKSW Salatiga, 2017). Kampus I UKSW memiliki luas keseluruhan $93.580 \mathrm{~m}^{2}$ berdasarkan sertifikat. Terdiri dari gedung perkuliahan, perpustakaan, gedung fakultas, lapangan dan gedung lain.

Berdasarkan data yang diperoleh, media informasi Kampus I UKSW dalam memperkenalkan institusinya kepada calon mahasiswa telah menggunakan berbagai cara, baik cara konvensional dengan kunjungan ke sekolah-sekolah menengah atas, menggunakan brosur dan melakukan presentasi. Media informasi bagi mahasiswa baru yang ada di area kampus terdiri dari media informasi cetak seperti brosur universitas, fakultas dan jurusan, majalah dinding, poster dan spanduk, sign system gedung, kelas, kantor fakultas, dan sign system penunjuk arah tempat-tempat lain di area kampus. Selain itu juga terdapat media informasi elektronik seperti website Universitas maupun fakultas. Media informasi untuk membantu mahasiswa mengenali wilayah kampus berupa peta dua dimensi hanya menyajikan informasi yang terbatas. Serta konten dalam peta berbeda dengan keadaan asli, karena adanya proses pembangunan dan alih fungsi gedung di wilayah kampus. Dari hasil wawancara dengan mahasiswa diperoleh kesimpulan bahwa mahasiswa mengalami kesulitan di dalam mencari letak gedung dan kelas pada saat awal masa perkuliahan. 
Informasi sangat penting dalam kehidupan manusia karena informasi dapat menambah pengetahuan dan kita juga dapat mengetahui hal-hal apa saja yang sedang terjadi dengan lingkungan kita pada saat ini (Sanjaya, 2006). Dengan berkomunikasi manusia diharapkan dapat mengetahui dan memahami semua informasi yang diperlukan. Namun tidak semua manusia dapat menerima dan memahami seluruh informasi dengan baik sehingga diperlukan sebuah media informasi yang tepat. Penyampaian komunikasi informasi pada era saat ini dapat diaplikasikan menggunakan perangkat multimedia. Proses pembelajaran dan penyampaian informasi dapat berlangsung menarik jika menggunakan multimedia (Wijaya, 2015). Salah satu pemanfaatan multimedia sebagai media informasi adalah teknologi virtual tour $360^{\circ}$.

Untuk mengatasi permasalahan informasi lokasi di Kampus I UKSW diperlukan sebuah media informasi yang tepat bagi mahasiswa untuk mendapatkan informasi wilayah kampus. Pada penelitian ini dirancang virtual tour sebagai media informasi dengan menggunakan teknologi panorama $360^{\circ}$. Virtual tour memiliki karakteristik menempatkan user seolah-olah berada di dalam gambar, dan user dapat bebas mengakses situasi virtual yang diciptakan dengan sudut pandang $360^{\circ}$. Virtual tour terdiri dari gabungan foto diambil dari sebuah sudut pandang secara panorama. Foto yang diambil dan kemudian dijahit sedemikian rupa untuk menciptakan realitas dengan cara terbaik. Virtual tour memungkinkan penggunanya bebas menjelajah ruangan-ruangan sebuah bangunan, melihat gambar, dan menikmati pemandangan dari sebuah lokasi, dengan sudut pandang $360^{\circ}$ (Navrotska, 2013). Dalam jurnal yang disusun oleh Osman, Wahab dan Ismail, Virtual Tour merupakan teknologi yang menempatkan user di dalam gambar dan memungkinkan user untuk meningkatkan kesadaran situasional serta meningkatkan daya lihat, tangkap dan menganalisa data virtual secara signifikan. Virtual Tour menunjukan kepada user keadaan sekitar yang mereka ingin ketahui (Osman, 2009). Virtual tour saat ini banyak diaplikasikan sebagai media promosi maupun media informasi. Beberapa tempat virtual tour yang paling terkenal adalah museum, daerah- daerah pariwisata, universitas, real estate, tempat bersejarah, taman dan daerah penangkaran, tempat-tempat umum seperti White House dan Taj Mahal, serta hotel dan motel (Henriette, 2004). Selain menampilkan suatu tempat, virtual tour digunakan untuk merepresentasikan sebuah gambar dari produk maupun jasa (Wisanto, 2015).

Virtual tour merupakan simulasi dari suatu lokasi berdasarkan realita dengan menggunakan foto panorama $360^{\circ}$ (reality photography). Virtual reality photography pada dasarnya memberikan simulasi pandangan seakan user berada di dalam gambar atau lokasi yang diabadikan oleh fotografer. Virtual reality photography diolah sedimikian rupa sehingga memungkinkan user untuk berinteraksi langsung dengan tempat virtual tersebut. Karakteristik virtual reality photography juga disebut immersive photography atau foto panorama $360^{\circ}$ adalah menampilkan suatu lokasi secara berkelanjutan (continously), tidak terpotong (seamless) dan tanpa tepi (borderless) dalam sudut pandang $360^{\circ}$ ke arah horizontal dan atau vertikal (Ma, 2011). Virtual tour memberikan gambaran sebuah lokasi berdasarkan kondisi nyata 
yang ada (Navrotska, 2013). Sehingga pemanfaatan virtual tour sebagai media informasi dapat memberikan informasi yang jelas bagi pengguna.

Data dari beberapa jurnal penelitian juga telah dilakukan penelitian pembuatan virtual tour sebagai media informasi di beberapa Universitas. Hasil penelitian yang menjadi referensi adalah skripsi yang berjudul Pengembangan Aplikasi Virtual Tour Berbantuan Video sebagai Media Informasi Wilayah Fakultas Teknik Universitas Negeri Yogyakarta, yang disusun oleh Farrizka Annafi, Program Studi Pendidikan Teknik Informatika Jurusan Pendidikan Teknik Elektronika Fakultas Teknik, Universitas Negeri Yogyakarta. Hasil penelitian tersebut adalah sebuah media informasi baru Fakultas Teknik Universitas Negeri Yogyakarta berupa aplikasi virtual tour untuk menyelesaikan permasalahan informasi wilayah yang ada di Fakultas Teknik Universitas Negeri Yogyakarta. Penelitian tersebut menjelaskan bahwa aplikasi virtual tour memberikan informasi lebih dini sebagai pengalaman lebih awal bagi mahasiswa dalam hal pengenalan wilayah Fakultas Teknik Universitas Negeri Yogyakarta. Aplikasi virtual tour sebagai media informasi dikatakan lebih efisien dan mendukung dibandingkan dengan media informasi yang telah ada, baik cetak maupun media online dengan informasi yang terbatas (Annafi, 2014).

Penelitian kedua yang menjadi referensi adalah jurnal yang berjudul Implementasi Sistem Virtual Tour Berbasis E-Panorama untuk Pengenalan Kampus Universitas Narotama Surabaya, yang disusun oleh Achmad Zakki Falani, Hendy Agha Satya Ramadan, dan Eman Setiawan, Fakultas IImu Komputer Universitas Narotama. Penelitian tersebut menghasilkan virtual tour berbasis e-panorama Universitas Narotama Surabaya, sebagai sarana yang lebih efektif dalam pengenalan Universitas Narotama Surabaya kepada masyarakat luas maupun calon mahasiswa (Falani 2016).

Perancangan Virtual Tour Kampus I UKSW ini membahas tentang kebutuhan akan media informasi mengenai tata letak gedung di Kampus I UKSW yang disampaikan secara informatif dan efektif dan dikemas dengan teknik panorama $360^{\circ}$. Perancangan virtual tour bertujuan sebagai media informasi lokasi gedung di Kampus I UKSW untuk mempermudah mahasiswa baru dalam mengenali wilayah dan letak gedung secara visual. Serta memberikan pengalaman virtual dalam mengakses wilayah Kampus I UKSW sebagai informasi awal kepada mahasiswa baru. Virtual tour ini bertujuan untuk memberikan informasi wilayah kampus kepada mahasiswa dengan menggunakan media yang interaktif. Interaktif media dalam perancangan media informasi publik sangatlah diperlukan dalam upaya pelayanan terhadap publik (Prabowo, 2015). Virtual tour yang dirancang diharapkan dapat menjadi rekomendasi perbaikan media informasi yang telah ada bagi mahasiswa baru untuk mengenali wilayah Kampus I UKSW.

\section{METODE PERANCANGAN}

Metode yang dilakukan dalam perancangan ini adalah pendekatan mixed method, karena dalam pengambilan data diperlukan wawancara dengan narasumber dan hasil yang kongkret dari audiens. Mixed method sendiri merupakan suatu metode 
penelitian yang mengkombinasikan atau menggabungkan antara metode kuantitatif dan metode kualitatif untuk digunakan secara bersama-sama dalam suatu kegiatan penelitian sehingga diperoleh data yang lebih komprehensif, valid, reliabel dan objektif (Sugiyono, 2011). Sedangkan strategi yang digunakan dalam penelitian ini yaitu menggunakan strategi linier dimana strategi linier menerapkan urutan logis pada tahapan perancangan yang sederhana dan relatif sudah dipahami komponennya (Sarwono, J \& Lubis, 2007). Adapun tahap-tahap yang digunakan dapat dilihat pada Gambar 1.

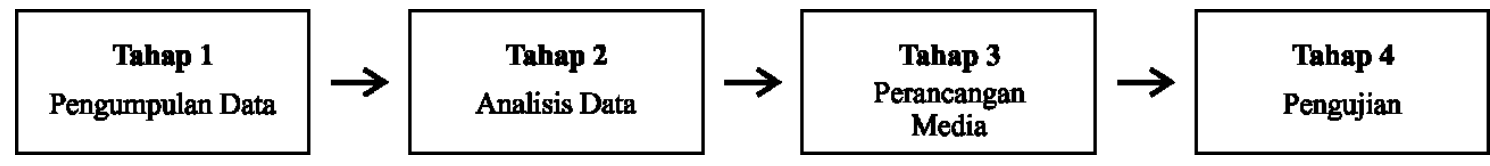

Gambar 1. Tahap penelitian strategi linier

[Sumber : Sarwono, J \& Lubis, 2007]

Beberapa tahap penelitian dalam strategi linier dijabarkan sebagai berikut :

a. Tahap Pengumpulan Data

Tahap ini merupakan proses melakukan observasi, dan melakukan wawancara dengan sumber terkait, yaitu kepada instansi UKSW, dan kepada mahasiswa. Data yang diperoleh dari proses pengumpulan data bertujuan untuk mengumpulkan informasi dan mengetahui permasalahan yang ada.

b. Tahap Analisis Data

Tahap ini merupakan proses mengembangkan ide dan menentukan langkah yang akan dilakukan dalam perancangan media, serta untuk menentukan karakteristik dan fitur yang dibutuhkan.

c. Tahap Perancangan Media

Tahap selanjutnya adalah perancangan media. Pada penelitian ini diperlukan tahapan dalam merancang sebuah virtual tour. Tahapan di dalam perancangan media terdiri dari proses pra-produksi, produksi dan pasca produksi sesuai dengan kebutuhan.

d. Tahap Pengujian

Tahap pengujian dilakukan untuk mengetahui virtual tour yang dirancang sesuai dengan tujuan atau tidak. Pengujian dilakukan dengan mixed metod, yaitu dengan melakukan wawancara kepada instansi UKSW, staff ahli bidang desain, dan membagikan kuesioner kepada mahasiswa.

\section{HASIL DAN PEMBAHASAN}

Pembahasan dari tahap penelitian yang dilakukan adalah sebagai berikut :

a. Pengumpulan data

Data dikumpulkan berdasarkan observasi langsung dan melakukan wawancara dengan Ibu Dra. Lina Sinatra Wijaya, MA selaku manajer Biro Promosi dan Hubungan Luar (BPHL) dan wawancara dengan Bapak Adi Susanto perwakilan pihak Biro Manajemen Kampus (BMK) bagian Pendayaan Pemeliharaan Aset, serta melakukan wawancara dengan mahasiswa. Tujuan wawancara adalah untuk mengetahui permasalahan media informasi di UKSW. 
Hasil wawancara dengan BPHL yaitu media informasi yang digunakan untuk memperkenalkan Kampus I UKSW berupa brosur dan website, serta kunjungan ke sekolah menengah atas (SMA) di berbagai wilayah Indonesia. Serta berdasarkan observasi di Kampus I UKSW, media informasi di lingkungan kampus untuk membantu mahasiswa mengenali wilayah kampus, yaitu berupa penunjuk arah kantor fakultas, sign system gedung dan kelas, sign system parkir, rambu-rambu kendaraan, majalah dinding, spanduk dan poster. Namun dari beberapa media informasi bagi mahasiswa baru, hanya bisa mengetahui lingkungan Kampus I UKSW secara terbatas. Untuk mengetahui wilayah kampus secara keseluruhan, mahasiswa harus datang di Kampus I UKSW secara langsung.

Untuk mengetahui informasi wilayah menggunakan peta kampus yang dapat diakses melalui website universitas. Namun peta kampus yang tersedia tidak update dan sudah kurang relevan dengan keadaan saat ini yaitu adanya proses pembangunan di wilayah kampus. Hasil wawancara dengan BMK diperoleh data informasi gedung, dan luas wilayah secara keseluruhan. Data yang diperoleh digunakan sebagai pertimbangan pembuatan skenario alur virtual tour.

Hasil wawancara dengan mahasiswa bertujuan untuk mengetahui tanggapan terhadap media informasi yang ada. Berdasarkan hasil wawancara dengan mahasiswa, diperoleh kesimpulan bahwa mahasiswa mengalami kesulitan di dalam mencari letak gedung dan kelas pada saat awal masa perkuliahan. Mahasiswa cenderung mencari informasi letak gedung dan kelas dengan bertanya. Beberapa mahasiswa berusaha mencari informasi terdahulu pada peta wilayah kampus, namun mahasiswa sependapat bahwa peta wilayah kampus kurang lengkap dan kurang informatif, serta sudah tidak relevan. Sign system di wilayah kampus cukup membantu di dalam penyampaian informasi, namun banyak mahasiswa yang kurang memanfaatkan sign system tersebut. Beberapa mahasiwa menyampaikan pendapat bahwa sign system tersebut kurang menarik dan menjadi alat penyampaian informasi yang ketinggalan zaman. Sign system bersusun dan terlalu kompleks dinilai kurang efektif karena mahasiswa harus meluangkan waktu untuk sekedar mendapatkan informasi dari sign system tersebut. Media informasi yang diharapkan oleh mahasiswa berupa denah wilayah kampus secara keseluruhan serta informatif, dilengkapi dengan gambar visual gedung sesuai dengan keaadaan aslinya, dan dimuat di website maupun sosial media. Peta kampus yang tersedia pada website kurang informatif dan tidak update, sehingga tidak dapat dijadikan sebagai acuan informasi. Media informasi berupa virtual tour yang diharapkan dapat memberikan informasi wilayah Kampus I UKSW secara keseluruhan, berupa gambar visual gedung sesuai keadaan aslinya. Virtual tour diharapkan dapat diaplikasikan pada website Universitas sehingga dapat diakses dengan mudah dan praktis oleh mahasiswa.

b. Analisis Data

Hasil analisis yang didapat yaitu, karakteristik media informasi media informasi berupa virtual tour yang dibutuhkan adalah virtual tour yang interaktif, 
menggambarkan letak wilayah gedung kantor, gedung perkuliahan, fasilitas yang ada di Kampus I UKSW berdasarkan gambar visual sesuai keadaan aslinya, dan mudah dipahami oleh mahasiswa. Fitur yang dibutuhkan yaitu hotspot. Hotspot merupakan titik interaktif pada sebuah virual tour yang digunakan untuk melakukan sesuatu seperti berpindah dari satu lokasi menuju lokasi lain pada virtual tour, maupun menuju alamat URL untuk membuka website. Fitur lain yaitu informasi nama gedung dan fasilitas, serta denah untuk menunjukkan lokasi terkini ketika menjelajah virtual tour.

\section{c. Perancangan Media}

Tahapan di dalam perancangan media terdiri dari proses pra-produksi, produksi dan pasca produksi yang sesuai dengan kebutuhan seperti pada Gambar 2.

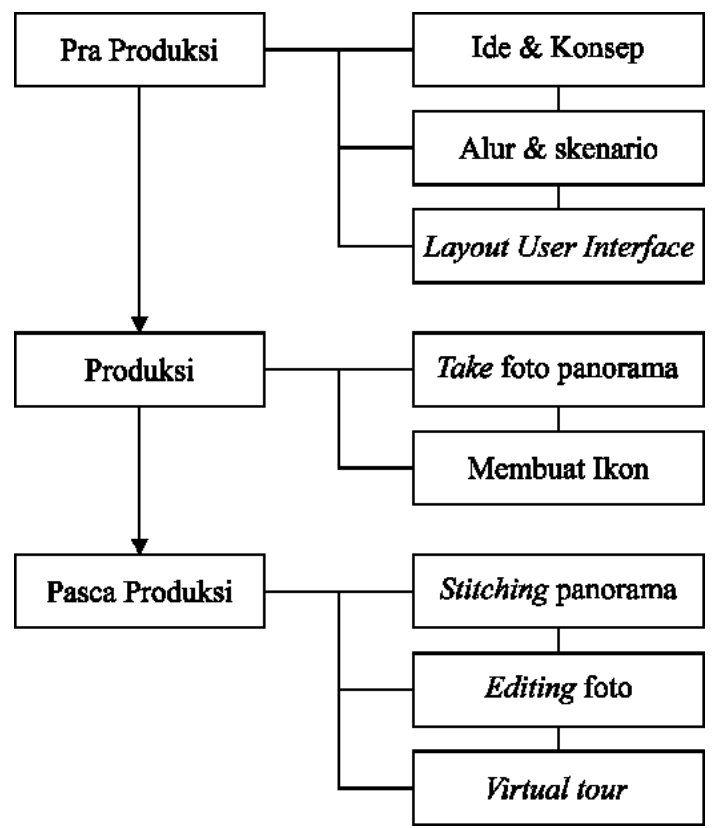

Gambar 2. Bagan metode perancangan [Sumber: Penulis]

Tahap pertama adalah proses pra-produksi, yaitu menentukan ide, merancang konsep, membuat alur dan skenario virtual tour. Ide perancangan media informasi adalah untuk memberikan informasi wilayah kampus kepada mahasiswa dengan menggunakan virtual tour dengan teknik panorama $360^{\circ}$. Konsep virtual tour dirancang dengan interface yang user friendly agar mudah diakses oleh mahasiswa untuk mencari informasi letak gedung dan fasilitas di wilayah kampus I UKSW.

Proses selanjutnya adalah membuat alur dan skenario virtual tour. Pembuatan alur yaitu menentukan titik / hotspot pada tempat-tempat strategis yang akan dilakukan proses pengambilan foto pada proses produksi, seperti pintu masuk dan keluar Kampus I UKSW, persimpangan jalan, gedung kantor, gedung perkuliahan, dan fasilitas yang ada di kampus I UKSW. Hotspot yang ditentukan berjumlah 60 titik. Setelah itu membuat skenario dengan menentukan titik awal memulai virtual tour. 
Virtual tour diawali dari pintu masuk Kampus I UKSW. Selanjutnya pengguna dapat menjelajah virtual tour Kampus I UKSW melalui akses hotspot yang tersedia.

Proses selanjutnya adalah merancang layout user interface, yaitu penataan menu dan fitur yang ada pada lembar kerja virtual tour. Proses merancang layout user interface bertujuan agar informasi yang disampaikan virtual tour dapat ditangkap dengan mudah oleh pengguna serta untuk memudahkan pengguna dalam menjalankan virtual tour. Proses perancangan layout user interface dapat dilihat pada Gambar 3.

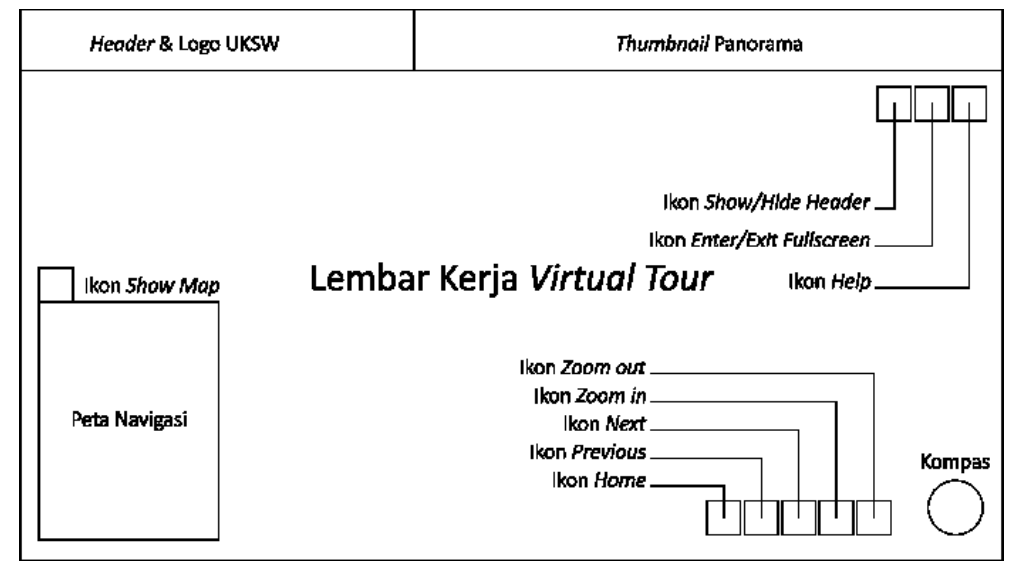

Gambar 3. Proses layout user interface [Sumber: Penulis]

Tahap berikutnya adalah proses produksi, yaitu take / pengambilan foto panorama. Foto diambil menggunakan teknik panorama $360^{\circ}$ pada setiap hotspot yang telah ditentukan. Foto diambil berurutan berputar $360^{\circ}$ dengan orientasi pengambilan secara portrait. Menggunakan lensa dengan sudut pandang yang luas dengan tujuan proses pengambilan foto yang efektif. Hasil dari proses pengambilan foto dapat dilihat pada Gambar 4.

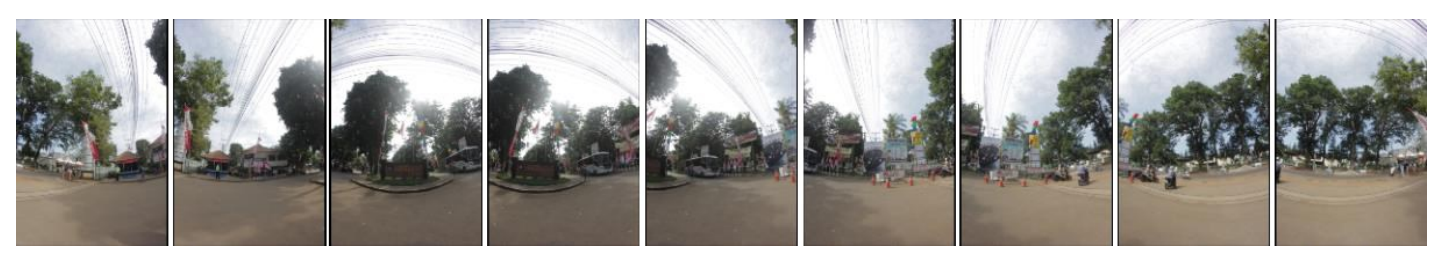

Gambar 4. Hasil pengambilan foto panorama $360^{\circ}$

[Sumber: Penulis]

Proses selanjutnya adalah membuat ikon menu dan fitur pada virtual tour. Menu pada virtual tour yaitu peta navigasi, tooltip informasi tempat dan gedung. Peta navigasi dibuat dengan gaya flat design yang memiliki karakter simpel dan jelas, menggunakan warna cerah dan kontras pada jalan dan antar gedung satu dengan yang lain, sehingga memudahkan didalam memahami peta navigasi. Peta navigasi dapat dilihat pada Gambar 5. 


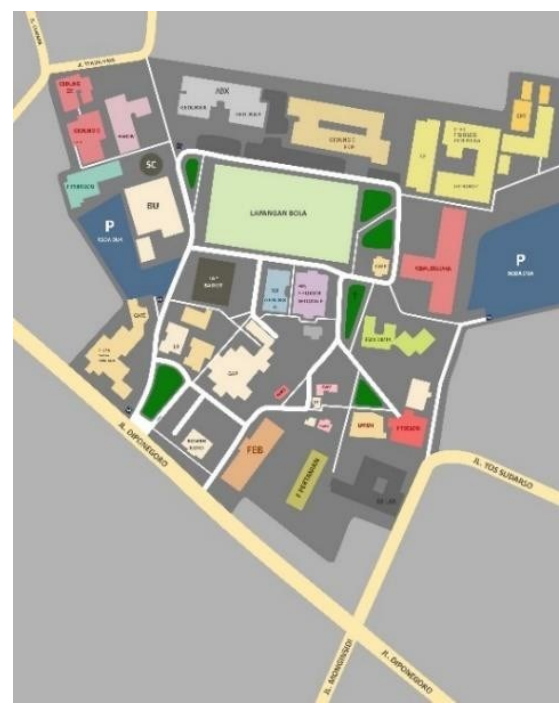

Gambar 5. Peta Navigasi

[Sumber: Penulis]

Tooltip informasi tempat dan gedung menggunakan font jenis sans serif yaitu Calibri Bold yang memiliki karakter simpel dan jelas, tidak memiliki masalah keterbacaan pada ukuran kecil maupun besar. Jenis font Calibri Bold dapat dilihat pada Gambar 6.

\title{
Aa Bb Cc Dd Ee Ff Gg Hh li Jj Kk Ll Mm Nn Oo Pp Qq Rr Ss Tt Uu Vv Ww Xx Yy Zz 1234567890,.!?()/
}

\author{
Gambar 6. Font Calibri Bold
}

[Sumber: Penulis]

Selanjutnya pembuatan ikon, merupakan fitur tombol navigasi pada virtual tour. Ikon fitur tombol navigasi bertujuan agar dapat membedakan antara fitur satu dan yang lain serta memudahkan didalam penggunaan. Tombol navigasi berwarna hitam menggambarkan kesan elegan, merupakan menu dasar seperti home, previous panorama, next panorama, zoom in, zoom out, enter/exit fullscreen, show/hide header. Tombol home untuk kembali ke tampilan awal virtual tour, yaitu pada pintu masuk. Previous panorama untuk menuju ke tampilan panorama sebelumnya dan next panorama untuk menuju ke tampilan panorama selanjutnya. Zoom in dan zoom out untuk memperbesar dan memperkecil tampilan virtual tour. Tombol enter/exit fullscreen untuk masuk/keluar pada tampilan layer penuh. Tombol show/hide header untuk menampilkan/menyembunyikan tampilan header dan thumbnail.

Tombol help berwarna pink menyala dan tombol show map berwarna oranye, kontras dengan tombol lainnya agar dapat langsung ditangkap oleh pengelihatan. Tombol help screen untuk menampilkan bantuan cara penggunaan dan informasi ikon-ikon yang ada pada virtual tour. Tombol show map untuk menampilkan peta 
navigasi. Hotspot tempat/gedung berwarna biru dengan garis tepi berwarna putih, berbentuk bulat dan berkedip-kedip menunjukkan tempat/gedung yang dapat di akses pada virtual tour. Hotspot penunjuk arah berbentuk oval, berwarna biru dengan garis tepi dan anak panah berwarna putih. Anak panah memberikan isyarat kepada pengguna untuk terus/lanjut menjelajah virtual tour. Hotspot tempat/gedung menampilkan tooltip informasi nama tempat/gedung secara langsung sedangkan hotspot penunjuk arah menampilkan tooltip pada saat kursor diletakkan di atas ikon. Ikon tombol navigasi dapat dilihat pada Gambar 7.

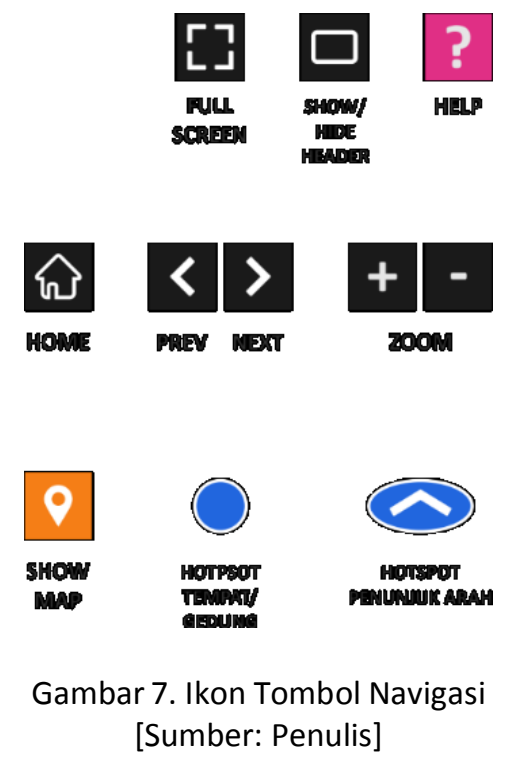

Tahap terakhir adalah proses pasca produksi yaitu stitching foto panorama, editing foto, dan pembuatan virtual tour. Proses stitching merupakan proses "menjahit" foto yang telah diambil menggunakan software khusus menjadi sebuah rangkaian foto panorama yang disusun secara spherical / membentuk bola. Pada proses ini, lighting / gelap-terang foto yang telah diambil dapat disesuaikan untuk menghasilkan pencahayaan yang merata. Proses stitching dapat dilihat pada Gambar 8.

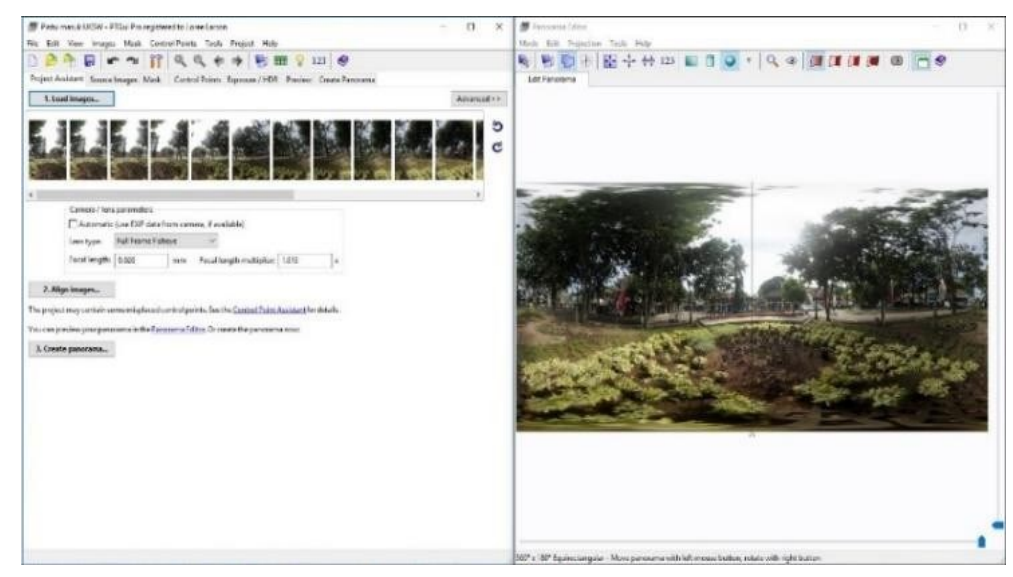

Gambar 8. Proses stitching

[Sumber: Penulis] 
Proses selanjutnya adalah editing foto yaitu menyesuaikan tone antar satu foto dengan yang lain. Selain itu dilakukan editing pada bagian-bagian foto yang kurang sempurna. Proses editing foto dapat dilihat pada Gambar 9.

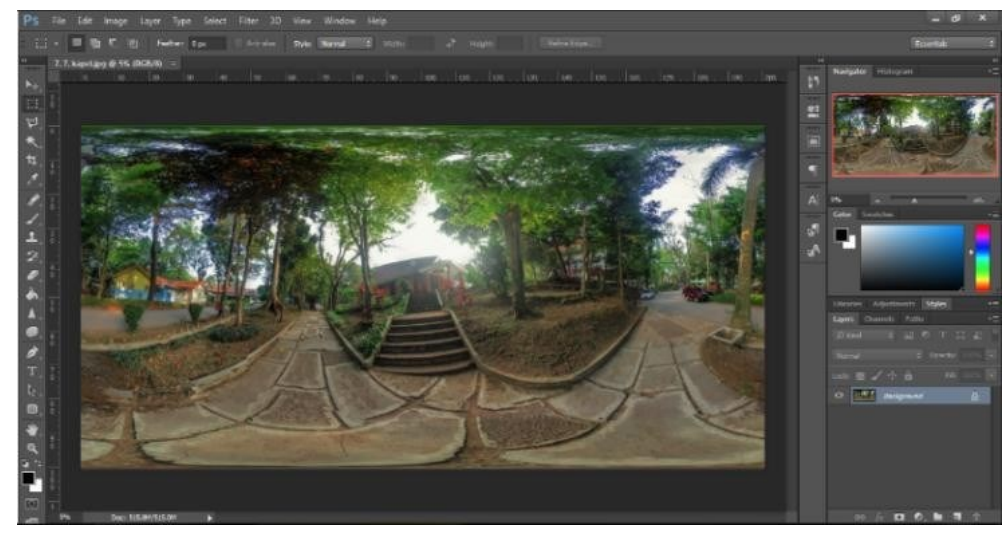

Gambar 9. Proses editing

[Sumber: Penulis]

Proses selanjutnya adalah pembuatan virtual tour yaitu menyusun hasil akhir foto panorama $360^{\circ}$ yang telah melewati proses editing sesuai alur yang telah ditentukan, sehingga menghasilkan foto panorama $360^{\circ}$ yang dapat dijelajah antara satu dengan yang lain. Proses perancangan virtual tour meliputi pembuatan hotspot pada titik yang telah ditentukan, serta penataan menu dan fitur pada lembar kerja sesuai layout yang telah dirancang. Proses pembuatan virtual tour dapat dilihat pada Gambar 10.

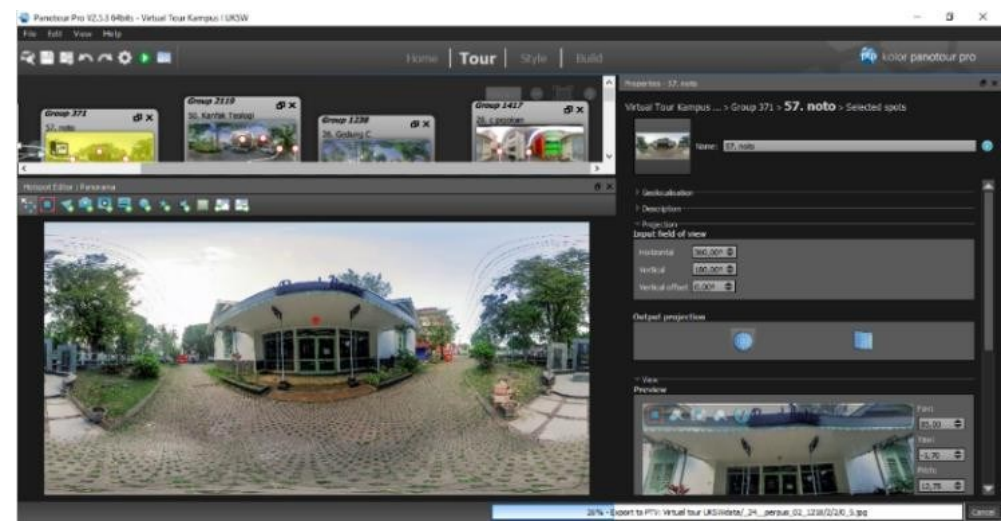

Gambar 10. Proses pembuatan virtual tour [Sumber: Penulis]

\section{d. Pengujian}

Pengujian dari perancangan virtual tour Kampus I UKSW sebagai media informasi mahasiswa baru menggunakan pendekatan mixed method. Pengujian pertama dilakukan melalui wawancara dengan Ibu Dra. Lina Sinatra Wijaya, MA selaku manajer BPHL UKSW tentang hasil perancangan, konten dan kelayakan virtual tour. Berdasarkan pengujian yang telah dilakukan dengan Ibu Dra. Lina Sinatra Wijaya, MA diperoleh hasil bahwa media informasi virtual tour yang telah dirancang sudah 
sesuai harapan, yaitu menyajikan informasi wilayah di Kampus I UKSW tentang letak gedung dan penunjuk arah saat melewati jalan, yang dapat diakses dengan mudah oleh pengguna. Virtual tour yang telah dirancang layak dimuat pada website UKSW sebagai media informasi wilayah Kampus I UKSW bagi mahasiswa baru.

Pengujian kedua dilakukan melalui wawancara dengan Bapak Jasson Prestiliano, ST., M.Cs selaku staff ahli di bidang desain, yang dimintai pertimbangan mengenai interface dan konten virtual tour. Berdasarkan pengujian yang telah dilakukan dengan Bapak Jasson Prestiliano, ST., M.Cs diperoleh hasil bahwa media informasi virtual tour yang telah dirancang memiliki ide dan konten yang menarik. Memberikan informasi kepada mahasiswa mengenai informasi letak gedung dengan seakan-akan berjalan di Kampus I UKSW. Interface yang disajikan pada virtual tour mudah diakses oleh pengguna, namun saran pada tooltip informasi tempat atau gedung perlu penambahan informasi dari tempat atau gedung tersebut.

Pengujian ketiga dilakukan dengan membagi kuisioner kepada mahasiswa. Data diperoleh dari dua puluh kuisioner yang dibagikan. Berikut adalah data yang diperoleh dari kuisioner, dapat dilihat pada tabel 1.

Tabel 1. Klasifikasi kualitas berdasarkan persentase [Sumber : Suharsimi, Arikunto. 2012]

\begin{tabular}{|c|c|}
\hline Persentase & Kategori \\
\hline $80 \%-100 \%$ & Sangat Tinggi \\
\hline $60 \%-79 \%$ & Tinggi \\
\hline $40 \%-59 \%$ & Cukup \\
\hline $20 \%-39 \%$ & Rendah \\
\hline$<20 \%$ & Sangat Rendah \\
\hline
\end{tabular}

Tabel 2. Data hasil kuisioner kepada mahasiswa

[Sumber: Dokumen penulis]

\begin{tabular}{|c|l|c|}
\hline No & \multicolumn{1}{|c|}{ Pertanyaan } & Hasil (\%) \\
\hline 1 & $\begin{array}{l}\text { Apakah mahasiswa mengalami permasalahan } \\
\text { informasi wilayah Kampus pada awal perkuliahan ? }\end{array}$ & $100 \%$ \\
\hline 2 & $\begin{array}{l}\text { Apakah peta Kampus pada website Universitas } \\
\text { memberikan informasi letak gedung? }\end{array}$ & $15 \%$ \\
\hline 3 & $\begin{array}{l}\text { Apakah mahasiswa sudah mengetahui tentang } \\
\text { virtual tour panorama 360 }\end{array}$ & $40 \%$ \\
\hline 4 & $\begin{array}{l}\text { Bagaimana keselumnya ? } \\
\text { dirancang dengan haran virtual tour yang }\end{array}$ & $85 \%$ \\
\hline 5 & $\begin{array}{l}\text { Bagaimana tingkat kelayakan virtual tour yang } \\
\text { dirancang mengenai informasi yang disajikan ? }\end{array}$ & $90 \%$ \\
\hline
\end{tabular}


Berdasarkan pengujian melalui kuisioner yang dilakukan, diperoleh hasil bahwa virtual tour yang dirancang sesuai dengan harapan mahasiswa sebagai media informasi letak gedung di Kampus I UKSW. Virtual tour yang dirancang menarik dan detail, sangat membantu mahasiswa baru untuk mencari letak gedung di Kampus I UKSW sehingga diperoleh kesimpulan bahwa virtual tour yang dirancang layak digunakan sebagai media informasi kepada mahasiswa baru.

Berikut adalah hasil Perancangan Virtual Tour Kampus I UKSW Sebagai Media Informasi Mahasiswa Baru yang telah dilakukan. Pada halaman awal virtual tour menampilkan splash screen berupa gambar bantuan cara menggunakan virtual tour, yaitu kontrol menggunakan perangkat mouse. Klik kiri dan drag untuk navigasi rotasi virtual tour, klik dua kali untuk tampilan fullscreen, serta scroll untuk zoom in dan zoom out. Ikon-ikon tombol navigasi virtual tour juga ditampilkan pada gambar. Tampilan awal virtual tour dapat dilihat pada Gambar 11.

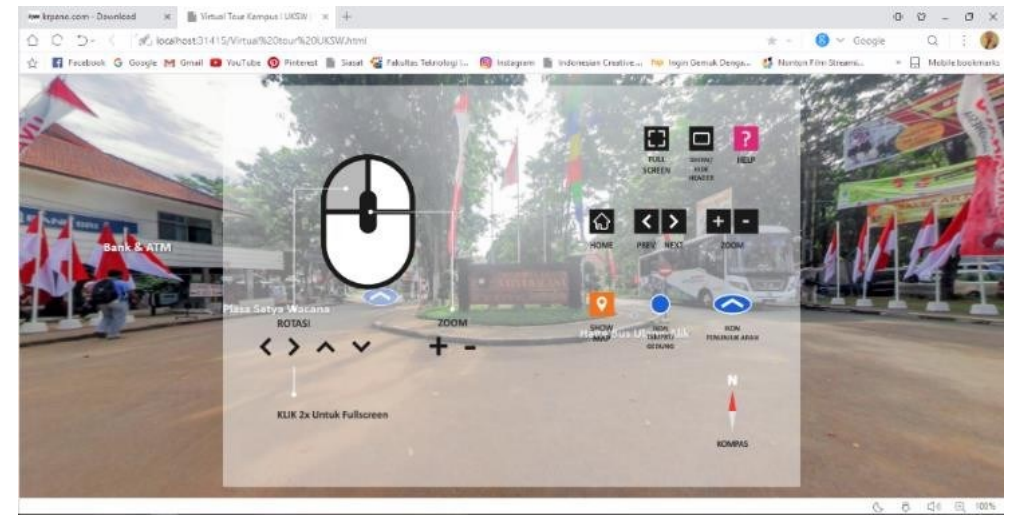

Gambar 11. Tampilan awal virtual tour [Sumber: Penulis]

Gambar bantuan dapat ditutup dengan meng-klik pada bagian gambar tersebut, dan dapat dibuka kembali dengan meng-klik tombol Help. Kemudian masuk pada tampilan virtual tour selanjutnya, yaitu tampilan user interface pada virtual tour dimana pengguna sudah dapat mengakses virtual tour sesuai kebutuhan dengan meng-klik hotspot yang ada. Tampilan user interface virtual tour dapat dilihat pada Gambar 12.

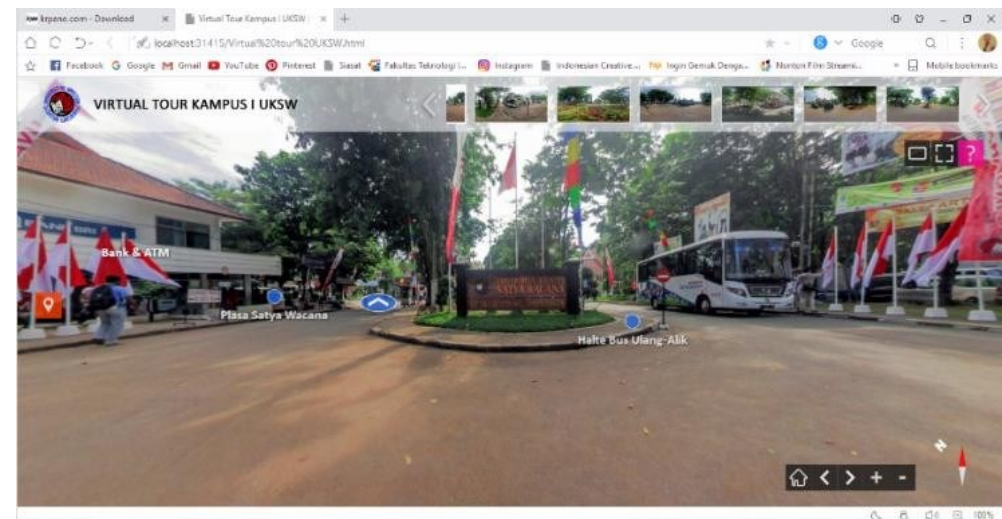

Gambar 12. Tampilan user interface virtual tour [Sumber: Penulis] 
Selanjutnya fitur yang terdapat pada virtual tour yaitu kompas yang terdapat pada sebelah kanan bawah tampilan lembar kerja virtual tour, thumbnail yang dapat menavigasi perpindahan virtual tour, dan peta navigasi yang dapat dibuka dan ditutup dengan meng-klik ikon peta pada sebelah kiri tampilan lembar kerja virtual tour. Peta navigasi menunjukkan situasi terkini pada saat mengakses virtual tour serta menampilkan radar berwarna biru yang memberikan informasi arah perputaran pada saat mengakses virtual tour. Tampilan virtual tour dengan peta navigasi dapat dilihat pada Gambar 13.

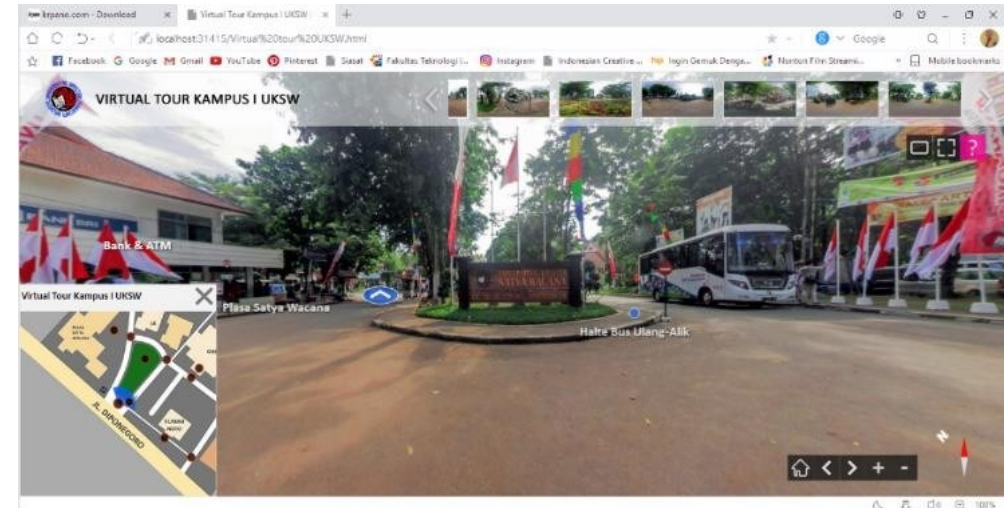

Gambar 13. Tampilan virtual tour dengan peta navigasi

[Sumber: Penulis]

\section{KESIMPULAN}

Berdasarkan hasil pengujian yang dilakukan, diperoleh kesimpulan bahwa Perancangan Virtual Tour Kampus I UKSW Sebagai Media Informasi Mahasiswa Baru dapat memberikan solusi terhadap masalah informasi wilayah Kampus I UKSW. Virtual tour yang dirancang dapat memberikan perbaikan terhadap media informasi yang telah ada, dengan karakter panorama $360^{\circ}$ yang menampilkan lokasi secara berkelanjutan ke dalam sudut pandang yang tidak terbatas, sehingga menghasilkan media informasi yang interaktif dan memliki daya tarik tersendiri. Informasi yang disampaikan melalui virtual tour sesuai harapan sebagai media informasi, serta sangat jelas dan detail mengenai letak gedung di Kampus I UKSW.

Berdasarkan hasil pengujian yang dilakukan, diperoleh saran yaitu informasi tambahan pada tempat atau gedung, sehingga pengguna dapat mengenali fungsi dari tempat atau gedung tersebut. Virtual tour yang dirancang layak untuk dimuat pada website UKSW sebagai media informasi wilayah Kampus I UKSW bagi mahasiswa baru, namun harus ada penyesuaian terlebih dahulu mengenai ukuran file yang terlalu besar.

\section{DAFTAR PUSTAKA}

Annafi, Farrizka. 2014. Pengembangan Aplikasi Virtual Tour Berbantuan Video sebagai Media Informasi Wilayah Fakultas Teknik Universitas Negeri Yogyakarta. Yogyakarta: Universitas Negeri Yogyakarta 
Falani, Achmad Zakki, 2016. Implementasi Sistem Virtual Tour Berbasis E-Panorama Untuk Pengenalan Kampus Universitas Narotama Surabaya. Surabaya: Universitas Narotama Surabaya

Ma, Dengzhe. 2011. Virtual Reality \& Augmented Reality in Industry. Shanghai: Shanghai Jiao Tong University Press

Navrotska, Uliana. 2013. Virtual Museum: Recreate The Reality. Milan : Politecnico Di Milano Polo Territoriale Di Como

Osman, Aznoora. 2009. Development and Evaluation of an Interactive 360. Journal of Information Technology Impact. Selangor : Universiti Teknologi MARA

Prabowo, D. P. (2015). Upaya Meningkatkan Pelayanan Informasi Kepada Masyarakat Menggunakan Media Interaktif Di Kantor Setda Kabupaten Grobogan. ANDHARUPA, 1(1), 71-83.

Sadiman, Arief S dkk. 2002. Media Pendidikan. Jakarta: PT Raja Grafindo Persada Orientasi Mahasiswa Baru UKSW Salatiga. 2017. Tentang UKSW. URL: http://omb.uksw.edu/tentang-uksw/ (Diakses 22 Nopember 2016)

Sanjaya, Wina. 2006. Strategi Pembelajaran Berorientasi Standar Proses Pendidikan. Jakarta: Kencana

Sarwono, J \& Lubis, H. 2007. Metode Riset Untuk Desain Komunikasi Visual. Yogyakarta: Penerbit Andi

Sobur, Alex. 2006. Semiotika Komunikasi. Bandung: PT Remaja Rosdakarya

Sugiyono. 2011. Metode penelitian kuantitatif kualitatif dan R\&D. Bandung: Alfabeta Suharsimi, Arikunto. 2012. Dasar-dasar Evaluasi Pendidikan edisi 2. Jakarta: Bumi Aksara.

Wijaya, David. 2015. Perancangan Media Informasi Berbasis Flash Pada Stmik Time Medan. Medan: STMIK Time Medan

Wisanto, Prabowo. 2015. Pembangunan Aplikasi Virtual Tour Kampus Universitas Komputer Indonesia. Bandung : Universitas Komputer Indonesia 